\title{
Safety of Abatacept Administered Intravenously in Treatment of Rheumatoid Arthritis: Integrated Analyses of up to 8 Years of Treatment from the Abatacept Clinical Trial Program
}

\author{
Michael E. Weinblatt, Larry W. Moreland, Rene Westhovens, Roger B. Cohen, Sheila M. Kelly, \\ Nader Khan, Ramesh Pappu, Ingrid Delaet, Allison Luo, Sheila Gujrathi, and Marc C. Hochberg
}

\begin{abstract}
Objective. To assess the overall safety, including rare events, of intravenous (IV) abatacept treatment in rheumatoid arthritis (RA).

Methods. Data from 8 clinical trials of IV abatacept in RA were pooled. Safety events were assessed during the short-term (duration $\leq 12$ months) and cumulative (short-term plus longterm extensions) abatacept treatment periods. Incidence rates per 100 patient-years were calculated. Standardized incidence ratios (SIR) for hospitalized infections and malignancies were compared with external RA cohorts and, for malignancies, with the US general population.

Results. There were 3173 IV abatacept-treated patients with 2331 patient-years of exposure in the short-term periods, and 4149 IV abatacept-treated patients with 12,132 patient-years of exposure in the cumulative period. Incidence rates for serious infections were low and consistent over time (3.68 for abatacept vs 2.60 for placebo during the short-term, and 2.87 for abatacept during the cumulative period). Hospitalized infections were generally similar to external RA patient cohorts and were consistent over time. Incidence rates of malignancies were similar for abatacept- and placebo-treated patients during the short-term period $(0.73$ vs 0.59$)$ and remained low during the abatacept cumulative period (0.73). SIR of some tissue-specific malignancies (e.g., colorectal and breast) in the cumulative period tended to be lower, while others (lymphoma and lung) tended to be higher, compared with the general population; however, incidence rates were comparable with RA cohorts. Autoimmune events were rare and infusion reactions uncommon.

Conclusion. Longterm safety of IV abatacept was consistent with the short-term, with no unexpected events and low incidence rates of serious infections, malignancies, and autoimmune events. (First Release April 15 2013; J Rheumatol 2013;40:787-97; doi:10.3899/jrheum.120906)
\end{abstract}

Key Indexing Terms:

RHEUMATOID ARTHRITIS T TELLS THERAPY TUBERCULOSIS

Abatacept is the first in a class of agents for rheumatoid arthritis (RA) that selectively modulates the CD80/ CD86:CD28 costimulatory signal required for $\mathrm{T}$ cell activation. Intravenous (IV) abatacept has demonstrated efficacy in patients with established RA refractory to disease-modifying antirheumatic drugs (DMARD), including methotrexate (MTX) $)^{1,2,3}$ and anti-tumor necrosis factor (TNF) therapy ${ }^{4}$. The safety of IV abatacept has been assessed in randomized, controlled trials (RCT) across multiple populations, including patients with background comorbidities (diabetes, chronic obstructive pulmonary disease, asthma, and congestive heart disease $)^{5}$. Across these populations, IV abatacept demonstrated acceptable safety and tolerability relative to its efficacy benefits $1,2,3,4,5,6,7$.
From Brigham and Women's Hospital, Boston, Massachusetts, USA; University of Pennsylvania Medical Center (UPMC) Arthritis and Autoimmunity Center, Pittsburgh, Pennsylvania, USA; Catholic University of Leuven, Leuven, Belgium; Fox Chase Cancer Center, Philadelphia, Pennsylvania; Bristol-Myers Squibb, Princeton, New Jersey; and University of Maryland School of Medicine, Baltimore, Maryland, USA.

Supported by Bristol-Myers Squibb. M.E. Weinblatt has received consulting fees and research grants from Bristol-Myers Squibb. R. Westhovens has received consulting fees from Bristol-Myers Squibb, Centocor Inc., Roche, and Schering-Plough; has participated in speaker bureaus for Bristol-Myers Squibb; and has received research grants from Roche and UCB Inc. R. Cohen has received consulting fees from Bristol-Myers Squibb. M.C. Hochberg is a consultant for Abbott Laboratories, Amgen, Bristol-Myers Squibb,

Genentech/Roche, and UCB Inc.
M.E. Weinblatt, MD, Brigham and Women's Hospital; L.W. Moreland, $M D, U P M C$ Arthritis and Autoimmunity Center; R. Westhovens, MD, $P h D$, Catholic University of Leuven; R.B. Cohen, MD, Fox Chase Cancer Center; S.M. Kelly, MD; N. Khan, MD; R. Pappu, PhD; I. Delaet, PhD; A. Luo, MD; S. Gujrathi, MD, Bristol-Myers Squibb; M.C. Hochberg, $M D, M P H$, University of Maryland School of Medicine.

Address correspondence to Dr. M.E. Weinblatt, Division of Rheumatology, Immunology and Allergy, Brigham and Women's Hospital, 75 Francis Street, Boston, MA 02115, USA.E-mail: mweinblatt@partners.org Full Release Article. For details see Reprints/Permissions at jrheum.org Accepted for publication February 8, 2013. Personal non-commercial use only. The Journal of Rheumatology Copyright (c) 2013. All rights reserved. 
Clinical trial and postmarketing surveillance data have indicated an increased risk of certain adverse events (AE) associated with biologic DMARD use: Mycobacterium tuberculosis (TB) and other opportunistic infections ${ }^{8}$, certain autoimmune events ${ }^{9,10}$, malignancies ${ }^{11,12}$, and infusion-site reactions ${ }^{13}$. Determining whether there is an increase in the risk of safety events with increasing biologic exposure is of particular clinical relevance given the chronic expression of the disease and longterm treatment required. By pooling data from a number of different trials, we are able to evaluate the incidence of safety events in a larger patient population with a greater total patient exposure in terms of combined patient-years compared with clinical trial reporting; such analysis allows identification of trends that may otherwise not be noted with smaller groups of patients with limited exposure. In addition, the incidence of safety events in longterm biologic-treated patients should be evaluated against the incidence in comparator cohorts of DMARD-treated patients and the overall population, to determine whether increased risks are associated with biologic treatment.

We pooled data from 8 trials from the IV abatacept clinical development program to evaluate safety in a large population of abatacept-treated patients with moderate to severe, established RA. Together, these studies include 12,132 patient-years of exposure with up to 8 years of treatment, representing the largest and longest analysis of this kind with abatacept, enabling an accurate evaluation of the safety of longterm treatment and versus comparator cohorts.

\section{MATERIALS AND METHODS}

Database. Data were pooled from 8 clinical trials of IV abatacept in adult patients with active, established RA with inadequate response to DMARD or anti-TNF therapy (Table 1). All studies consisted of short-term periods of $\leq 12$ months' duration and subsequent open-label longterm extensions (LTE), and included 2 phase II (NCT00162266 and NCT00162279) ${ }^{1,14}$ and 4 phase III (NCT00048568, NCT00048581, NCT00048932, and NCT00095147) 2,4,5,15 RCT, and 2 open-label trials (NCT00162201 and NCT00162201 $)^{16,17}$. Data are reported for the pooled short-term period according to abatacept or placebo treatment arm, and for the cumulative trial periods, which included data from both the short-term and open-label LTE of the studies. The cumulative analysis period comprised patients who received $\geq 1$ dose of IV abatacept at any time, regardless of treatment in the short-term period. Data from the phase III trial of IV abatacept in early RA ${ }^{7}$ were not included; the current safety analysis was initiated prior to this phase III study, and comprised a different population compared with our analysis (i.e., early in contrast to established RA). All patients were screened for TB; TB-positive patients were excluded, except in 1 open-label trial in anti-TNF inadequate responders ${ }^{17}$ and 1 double-blind trial in MTX inadequate responders ${ }^{15}$. In these studies, TB-positive patients were included if they had appropriate treatment and a negative chest radiograph at enrollment ${ }^{17}$

Safety evaluation. All patients were monitored for AE and serious AE (SAE); safety information was obtained at each study visit through the

Table 1. Intravenous abatacept rheumatoid arthritis (RA) safety database. Data available up to November 2009.

\begin{tabular}{|c|c|c|c|c|}
\hline \multirow[t]{2}{*}{ Study } & \multirow[t]{2}{*}{ Patient Population } & \multirow{2}{*}{$\begin{array}{c}\text { Interventions and Concomitant Medications } \\
\text { During Short-term Periods* }\end{array}$} & \multicolumn{2}{|c|}{ Numbers } \\
\hline & & & $\begin{array}{l}\text { Short-term } \\
\text { Period }^{\dagger}\end{array}$ & $\begin{array}{l}\text { Cumulative } \\
\text { Period }^{\dagger \#}\end{array}$ \\
\hline $\begin{array}{l}\text { Phase IIb RCT abatacept plus } \\
\text { etanercept } \\
\quad(\text { NCT00162279) })^{14}\end{array}$ & Etanercept inadequate responders & $\begin{array}{l}\text { Abatacept } 2 \mathrm{mg} / \mathrm{kg} / \mathrm{mo} \text { vs placebo, plus } \\
\text { etanercept } 25 \mathrm{mg} \text { (twice weekly) }\end{array}$ & 85 & 107 \\
\hline $\begin{array}{l}\text { Phase III RCT ATTAIN } \\
(\text { NCT00048581 })^{4}\end{array}$ & Anti-TNF inadequate responders & $\begin{array}{l}\text { Abatacept } 10 \mathrm{mg} / \mathrm{kg} \text { vs placebo, plus } \\
\text { background nonbiologic DMARD }\end{array}$ & 258 & 357 \\
\hline $\begin{array}{l}\text { Phase III RCT ASSURE } \\
(\text { NCT00048932) }\end{array}$ & DMARD or biologic inadequate responders & $\begin{array}{c}\text { Abatacept } 10 \mathrm{mg} / \mathrm{kg} \text { vs placebo, plus } \\
\text { background DMARD and/or biologic therapy }\end{array}$ & 959 & 1343 \\
\hline $\begin{array}{l}\text { Phase III RCT ATTEST } \\
(\text { NCT00095147) }\end{array}$ & MTX inadequate responders & $\begin{array}{c}\text { Abatacept } 10 \mathrm{mg} / \mathrm{kg} \text { vs infliximab } 3 \mathrm{mg} / \mathrm{kg} \text { vs } \\
\text { placebo, plus background MTX }\end{array}$ & 156 & 399 \\
\hline Total & & & 3173 & 4149 \\
\hline
\end{tabular}

* Patients switched to open-label intravenous (IV) abatacept $(\sim 10 \mathrm{mg} / \mathrm{kg}$ according to weight range) if they entered the open-label longterm extensions, during which changes to concomitant and background medications were permitted. ${ }^{\dagger}$ Patients receiving IV abatacept. ${ }^{\#}$ Some patients from other treatment groups crossed over to IV abatacept treatment duing open-label extensions. RCT: randomized controlled trial; MTX: methotrexate; AIM: Abatacept in Inadequate responders to Methotrexate; ATTAIN: Abatacept Trial in Treatment of Anti-TNF INadequate responders; TNF: tumor necrosis factor; DMARD: disease-modifying antirheumatic drug; ASSURE: Abatacept Study of Safety in Use with other RA therapies; ATTEST: Abatacept or infliximab versus placebo, a Trial for Tolerability, Efficacy and Safety in Treating RA; MoA: mechanism of action; ARRIVE: Abatacept Researched in RA patients with an Inadequate anti-TNF response to Validate Effectiveness.

Personal non-commercial use only. The Journal of Rheumatology Copyright (C) 2013. All rights reserved 
short-term periods, and monthly during the LTE. For patients who dropped out of any study, in either the short-term or LTE periods, AE that occurred up to 56 days (or 60 days for phase II studies) following the last dose of study medication were included in this analysis. Events were classified using the Medical Dictionary for Regulatory Activities (MedDRA) classification. Acute infusional events and autoimmune events were prespecified based on MedDRA preferred terms. The incidence of hospitalized infections and malignancies with abatacept were compared with the expected incidence in the DMARD-treated RA population. RA cohorts were selected if they included comparable patient populations including patients receiving only nonbiologic DMARD, and could provide age- and sex-specific incidence rates (IR) for the specified outcomes (Table 2). Hospitalized infections with abatacept were compared with 2 RA cohorts: the British Columbia (BC) RA Cohort and a PharMetrics claims database $^{18,19}$. Malignancies with abatacept were compared with 3 external RA cohorts: the BC RA Cohort, the National Data Bank for Rheumatic Diseases in the United States, and the General Practice Research Database in the United Kingdom ${ }^{18,20,21}$. For malignancies, standardized incidence ratios (SIR) were also computed using US general population data from the Surveillance Epidemiology and End Results database as a comparator ${ }^{22}$.

Statistics. Safety analyses were not hypothesis-driven; no formal statistical testing was performed.

Incidence rates (number of patients with event divided by total exposure for the treatment period; expressed as events/100 patient-yrs with 95\% CI) were calculated for the short-term period (IV abatacept- and placebo-treated patients) and the cumulative period (total and yearly intervals). Exposure to study drug is defined as the number of months a patient was known to be on study drug, summed together for each patient to give the total cumulative exposure. As such, patients contributed different exposure lengths to the total cumulative exposure. The contribution to the total exposure time for each patient ended at the first occurrence of the AE. SIR with 95\% CI were calculated for hospitalized infections and malignancies for abatacept treatment versus comparator cohorts, adjusted for age and $\operatorname{sex}^{23}$. SIR $(95 \% \mathrm{CI})$ were computed by dividing the observed numbers of events with abatacept in the cumulative treatment period by the expected numbers based on event rates in the comparator cohorts.

\section{RESULTS}

Patients. The short-term analysis included 3173 and 1099 patients treated with abatacept and placebo, respectively, during the pooled short-term study periods. A total of 4149 patients received at least 1 dose of abatacept in either the short-term or open-label LTE periods, and are included in the cumulative population. The numbers of patients included from each abatacept clinical trial are shown in Table 1.

Baseline data for the pooled short-term and cumulative populations are presented in Table 3. Although there were differences in the baseline data across the individual studies included, demographics and characteristics were similar between IV abatacept- and placebo-treated patients and were comparable for patients in the short-term and in cumulative populations.

Exposure. During the short-term period, abatacept-treated patients had 2331 patient-years of exposure in total; median exposure was 11.7 months (range 1.9-13.8). The cumulative period included 12,132 patient-years of exposure and median exposure was 31.7 months (range 1.9-104.2). Of the 4149 patients treated in the cumulative treatment period, $3.4 \%$ of patients were exposed to abatacept for $<3$ months; $26.2 \%$ for 3 to $<12$ months; $13.1 \%$ for 12 to $<24$ months; $10.7 \%$ for 24 to $<36$ months; $7.3 \%$ for 36 to $<48$ months; $11.4 \%$ for 48 to $<60$ months; and $28.0 \%$ for $\geq 60$ months.

Adverse events. The IR of SAE were comparable (with overlapping 95\% CI) for placebo- and abatacept-treated patients in the short-term periods, with no increase in IR for the cumulative study period (Table 4).

The IR of discontinuations due to AE was numerically higher for abatacept- versus placebo-treated patients, and decreased in the cumulative versus short-term periods for abatacept-treated patients (Table 4). AE leading to discontinuation during the short-term period (occurring in 3 or more patients) included pneumonia, bronchitis, localized

Table 2. Comparator cohorts.

\begin{tabular}{|c|c|c|c|}
\hline Rheumatoid Arthritis Cohorts & Description & $\begin{array}{l}\text { Hospitalized } \\
\text { Infections }\end{array}$ & Malignancies \\
\hline British Columbia, Canada, RA cohort ${ }^{18}$ & $\begin{array}{l}\text { Administrative data on physician visits, hospitalizations, and } \\
\text { medications, collected between } 1996 \text { and } 2001 \text {. } \\
\mathrm{N}=12,337 \text { DMARD-treated patients }\end{array}$ & $\checkmark$ & $\checkmark$ \\
\hline PharMetrics claims database ${ }^{19}$ & $\begin{array}{l}\text { A US integrated managed care database including data from pharmacy, } \\
\text { provider, and facility claims for members enrolled in } 61 \text { health plans } \\
\text { across the US from } 1998 \text { to } 2002 \text {. } \\
\mathrm{N}=122,272 \text { RA patients }\end{array}$ & $\checkmark$ & \\
\hline $\begin{array}{l}\text { National Data Bank for Rheumatic Diseases, } \\
\text { United States (NDB) }{ }^{20}\end{array}$ & $\begin{array}{l}\text { Longitudinal cohort reported on patient questionnaire between } 1998 \text { and } \\
2003 \text {. } \\
N=10,499 \text { DMARD-treated patients }\end{array}$ & & $\checkmark$ \\
\hline $\begin{array}{l}\text { General Practice Research Database, } \\
\text { United Kingdom (GPRD) })^{21}\end{array}$ & $\begin{array}{l}\text { Electronic medical records between } 1987 \text { and } 2001 \\
\mathrm{~N}=14,467 \text { DMARD-treated patients }\end{array}$ & & $\checkmark$ \\
\hline $\begin{array}{l}\text { US general population: Surveillance } \\
\text { Epidemiology and End Results (SEER) } \\
\text { database }^{22}\end{array}$ & $\begin{array}{l}\text { The SEER Program of the national Cancer Institute provides information } \\
\text { on cancer statistics from various locations and sources throughout the } \\
\text { United States. Data here are based on SEER 17, collected 2000-2007. } \\
\mathrm{N}=79,021,933 \text { participants }\end{array}$ & & $\checkmark$ \\
\hline
\end{tabular}

DMARD: disease-modifying antirheumatic drug; RA: rheumatoid arthritis. Personal non-commercial use only. The Journal of Rheumatology Copyright @ C 2013. All rights reserved. 
Table 3. Baseline demographics and clinical characteristics for the short-term and cumulative populations.

\begin{tabular}{lccc}
\hline & \multicolumn{2}{c}{$\begin{array}{c}\text { Short-term Period } \\
\text { IV Abatacept }+ \\
\text { Characteristic }\end{array}$} & $\begin{array}{c}\text { Cumulative Period, } \\
\mathrm{n}=4149\end{array}$ \\
& $\begin{array}{c}\text { Background Therapy, } \\
\mathrm{n}=1099\end{array}$ & $\begin{array}{c}\text { Background Therapy, } \\
\mathrm{n}=3173\end{array}$ \\
\hline Mean age, yrs (SD) & $51.9(12.0)$ & $53.0(12.3)$ & $52.6(12.2)$ \\
Sex (female), n (\%) & $884(80.4)$ & $2536(79.9)$ & $3335(80.4)$ \\
Race (white), $\mathrm{n}(\%)$ & $948(86.3)$ & $2824(89.0)$ & $3651(88.0)$ \\
Mean disease duration, yrs (SD) & $9.7(8.6)$ & $10.4(8.9)$ & $10.1(8.8)^{*}$ \\
Mean physical function, HAQ-DI score (SD) & $1.5(0.7)$ & $1.6(0.6)$ & $1.6(0.7)$ \\
Mean CRP, mg/dl (SD) & $2.6(2.9)$ & $2.5(3.0)$ & $2.5(2.9)^{\dagger}$ \\
Patients receiving MTX, n (\%) & $919(83.6)$ & $2491(78.5)$ & $3332(80.3)$ \\
Patients receiving other DMARD, n (\%) & $259(23.6)$ & $861(27.1)$ & $1076(25.9)$ \\
Patients receiving biologic RA therapy, n (\%) & $84(7.6)$ & $239(7.5)$ & $296(7.1)$ \\
Anti-TNF therapy, n (\%) & $74(6.7)$ & $217(6.8)$ & $265(6.4)$ \\
Anakinra, $\mathrm{n}(\%)$ & $10(0.9)$ & $26(0.8)$ & $35(0.8)$ \\
Rituximab, n (\%) & 0 & $1(<0.1)$ & $1(<0.1)$ \\
\hline
\end{tabular}

$* \mathrm{n}=4130 ;{ }^{\dagger} \mathrm{n}=4136$. HAQ-DI: Health Assessment Questionnaire-Disability Index; MTX: methotrexate; DMARD: disease-modifying antirheumatic drug; TNF: tumor necrosis factor; CRP: C-reactive protein; RA: rheumatoid arthritis; IV: intravenous.

Table 4. Overview of adverse events (AE) in the short-term and cumulative analyses from the 8 integrated trials. Data show incidence rates (IR) per 100 patient-years (95\% Poisson CI). An AE was defined as any new or worsening illness, sign, symptom, or clinically significant laboratory test abnormality during the course of the trial, regardless of causality. A serious adverse event (SAE) was defined as an AE that was fatal; life-threatening; resulted in or prolonged hospitalization; resulted in persistent or significant disability or incapacity; cancer; a congenital anomaly/birth defect; resulted in an overdose, development of drug dependency or drug abuse; or thought to be an important medical event.

\begin{tabular}{|c|c|c|c|c|}
\hline & & \multicolumn{2}{|c|}{ Short-term Period } & \multirow{2}{*}{$\begin{array}{c}\text { Cumulative Period, } \\
n=4149\end{array}$} \\
\hline & & $\begin{array}{c}\text { Placebo }+ \\
\text { Background Therapy Total, } \\
\mathrm{n}=1099\end{array}$ & $\begin{array}{c}\text { IV Abatacept }+ \\
\text { Background Therapy Total, } \\
n=3173\end{array}$ & \\
\hline \multirow[t]{2}{*}{ Total SAE } & Patients with event, $\mathrm{n}$ & 136 & 399 & 1373 \\
\hline & IR $(95 \%$ CI $)$ & $16.90(14.18,19.99)$ & $18.10(16.37,19.97)$ & $14.61(13.85,15.41)$ \\
\hline Discontinuations due to $\mathrm{AE}$ & Patients with event, $\mathrm{n}$ & 40 & 158 & 426 \\
\hline Deaths & IR (95\% CI) & $0.82(0.33,1.69)$ & $0.51(0.27,0.90)$ & $0.60(0.47,0.76)$ \\
\hline
\end{tabular}

infection, dizziness, headache, cough, cardiac congestive failure, breast cancer, malignant lung neoplasm, rash, asthenia, chest pain, aphthous stomatitis, nausea, RA, leukopenia, and back pain.

Deaths. Causes of death in the short-term period (Table 4) included cardiac disorders $(n=7)$, infections $(n=2)$, malignancies $(n=1)$, and other causes $(n=4)$ for abatacept-treated patients, and cardiac disorders $(n=3)$, infections $(n=2)$, malignancies $(n=2)$, and other causes ( $n$ = 3) for placebo-treated patients; more than 1 cause was cited per patient. The most frequently cited cause of death for abatacept-treated patients in the cumulative period was cardiac disorder $(n=26)$; remaining causes included infections $(\mathrm{n}=13)$, malignancies $(\mathrm{n}=13)$, respiratory, thoracic and mediastinal disorders $(\mathrm{n}=10)$, vascular disorders $(\mathrm{n}=$ $5)$, or other causes $(n=21)$. The following infections resulted in death: pneumonia $(n=6)$, septic shock $(n=5)$, sepsis $(\mathrm{n}=3)$, bronchopulmonary aspergillosis $(\mathrm{n}=2)$, aspergillosis, Clostridium difficile colitis, Enterobacter pneumonia, human ehrlichiosis, lobar pneumonia, sinusitis, staphylococcal bacteremia, systemic mycosis, and staphylococcal wound infections ( $\mathrm{n}=1$ for each).

Infections. The IR of infections and the most common types were comparable between abatacept- and placebo-treated patients during the short-term period (Table 5). The IR of infections were reduced in the cumulative versus short-term periods, and the annual IR for hospitalized infections remained consistent with increasing exposure (Figure 1A).

During the short-term period, the IR of viral infections were comparable between groups (43.74 vs 42.64/100 patient-yrs for abatacept vs placebo, respectively). Herpes simplex was slightly more common for abatacept versus placebo (0.52 vs $0.23 / 100$ patient-yrs), and herpes zoster 
Table 5. Overview of infections in the short-term and cumulative periods from the 8 integrated trials. Data show incidence rates (IR) per 100 patient-years (95\% Poisson CI)

\begin{tabular}{|c|c|c|c|c|}
\hline & & Short & iod & Cumulative Period, \\
\hline & & $\begin{array}{l}\text { Placebo, } \\
\mathrm{n}=1099\end{array}$ & $\begin{array}{c}\text { IV Abatacept, } \\
\mathrm{n}=3173\end{array}$ & $\mathrm{n}=4149$ \\
\hline & $\mathrm{IR}(95 \% \mathrm{CI})$ & $92.46(84.81,100.62)$ & $98.00(93.20,102.99)$ & $75.68(73.00,78.44)$ \\
\hline Serious infections & Patients with event, $\mathrm{n}$ & 22 & 85 & 332 \\
\hline & IR $(95 \%$ CI $)$ & $2.60(1.63,3.94)$ & $3.68(2.94,4.55)$ & $2.87(2.57,3.19)$ \\
\hline Most frequently reported infections & (IR $\geq 6.0 / 100$ patient-yr & nts receiving abatacept & & \\
\hline Upper respiratory tract infection & Patients with event, $\mathrm{n}$ & 133 & 346 & 990 \\
\hline & IR $(95 \%$ CI $)$ & $16.78(14.05,19.88)$ & $15.82(14.19,17.57)$ & $10.18(9.56,10.84)$ \\
\hline Nasopharyngitis & Patients with event, $\mathrm{n}$ & 98 & 280 & 819 \\
\hline & IR $(95 \%$ CI $)$ & $12.17(9.88,14.83)$ & $12.71(11.27,14.29)$ & $8.38(7.82,8.97)$ \\
\hline Bronchitis & Patients with event, $\mathrm{n}$ & 60 & 193 & 673 \\
\hline & IR $(95 \% \mathrm{CI})$ & $8.87(6.95,11.15)$ & $8.82(7.64,10.13)$ & $5.41(4.98,5.86)$ \\
\hline Most frequency reported serious in & ections (IR $\geq 0.25 / 100 p$ & for patients receiving al & t any time) & \\
\hline Pneumonia & Patients with event, $\mathrm{n}$ & 5 & 15 & 55 \\
\hline & IR $(95 \% \mathrm{CI})$ & $0.59(0.19,1.37)$ & $0.64(0.36,1.06)$ & $0.46(0.34,0.59)$ \\
\hline Bronchitis & Patients with event, $\mathrm{n}$ & 0 & 7 & 19 \\
\hline & IR $(95 \% \mathrm{CI})$ & 0 & $0.30(0.12,0.62)$ & $0.16(0.09,0.25)$ \\
\hline Cellulitis & Pateints with event, $\mathrm{n}$ & 2 & 5 & 22 \\
\hline & IR $(95 \%$ CI) & $0.23(0.03,0.85)$ & $0.21(0.07,0.50)$ & $0.18(0.11,0.28)$ \\
\hline Urinary tract infection & Patients with event, $\mathrm{n}$ & 1 & 5 & 24 \\
\hline & IR $(95 \%$ CI $)$ & $0.12(0,0.65)$ & $0.21(0.07,0.50)$ & $0.20(0.13,0.30)$ \\
\hline
\end{tabular}

was comparable between groups (1.77 vs 2.01/100 patient-yrs for abatacept vs placebo). The IR of viral infections, herpes simplex, and herpes zoster during the cumulative period $(31.89,0.37$, and $1.51 / 100$ patient-yrs, respectively) remained consistent with those in the short-term period. No cytomegalovirus or Epstein-Barr virus infections were reported.

In total, 44 patients reported opportunistic infections (IR of $0.36 / 100$ patient-yrs), including TB $(n=8 ; 0.07 / 100$ patient-yrs) and esophageal/oropharyngeal candidiasis $(\mathrm{n}=$ 6; 0.05/100 patient-yrs). There was 1 case of bronchopulmonary aspergillosis in the abatacept group during the short-term period, and no cases of coccidioidomycosis, cryptococcus, histoplasmosis, nocardiosis, or Pneumocystis jiroveci pneumonia.

Two cases of suspected TB were reported during the short-term period, 1 each for IV abatacept and placebo. The abatacept-treated patient was diagnosed with TB localized in a ganglionar (nodal) mass based on histological findings (necrotizing and suppurative granulomatous inflammation) although a Ziehl-Neelsen stain was negative for TB and no acid-fast bacilli (AFB) were identified. The patient, a 55-year-old Hispanic female, had a negative purified protein derivative (PPD) tuberculin skin test and chest radiograph prior to starting abatacept. Therapy was discontinued, TB treatment was initiated, and the patient did not exhibit any other clinical signs of TB. The placebo-treated patient was a 49-year-old white South American male (dosing was interrupted and TB treatment initiated; the event subsequently resolved). Although 26 patients were PPD-positive at entry into 1 of the open-label trials (per protocol), none of these abatacept-treated patients developed $\mathrm{TB}^{17}$. Annual IR of TB remained stable with increasing exposure to IV abatacept. Each of the TB cases tended to occur within 1-3 years of treatment. There were 7 further TB reports during the cumulative period: 1 report each of latent $\mathrm{TB}$, bone $\mathrm{TB}$ [positive PPD and computed tomography (CT) scan; potentially Pott's disease, not formally diagnosed], lymph node TB (caseating granuloma), TB pleurisy [elevated adenosine deaminase in pleural fluid $(38 \mathrm{U} / \mathrm{ml})]$, and 3 pulmonary TB reports (1 with bacteriological confirmation, 1 with positive $\mathrm{AFB}$, and 1 with positive PPD and CT scan). No cases resulted in death.

The number of hospitalized infections with abatacept was lower than expected compared with the BC (SIR 0.85, $95 \%$ CI $0.8,1.0$ ) and PharMetrics (SIR $0.73,95 \%$ CI 0.6 , 0.8 ) databases.

Malignancies. The IR of malignancies [excluding Personal non-commercial use only. The Journal of Rheumatology Copyright (c) 2013. All rights reserved. 


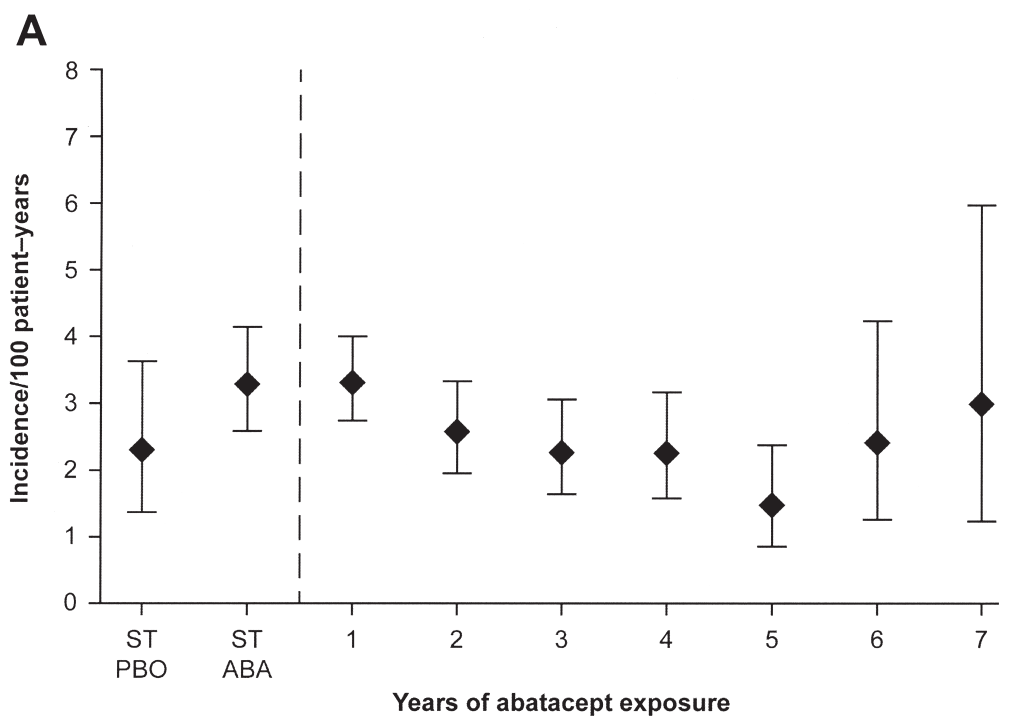

\begin{tabular}{|l|c|c|c|c|c|c|c|c|c|}
\hline & ST & ST & Year & Year & Year & Year & Year & Year & Year \\
& PBO & ABA & $\mathbf{1}$ & $\mathbf{2}$ & $\mathbf{3}$ & $\mathbf{4}$ & $\mathbf{5}$ & $\mathbf{6}$ & $\mathbf{7}$ \\
\hline Patients with event, $\mathbf{n}$ & 20 & 77 & 118 & 65 & 46 & 38 & 19 & 13 & 8 \\
\hline Incidence/100 patient-years & 2.36 & 3.33 & 3.35 & 2.63 & 2.31 & 2.33 & 1.55 & 2.48 & 3.03 \\
\hline
\end{tabular}

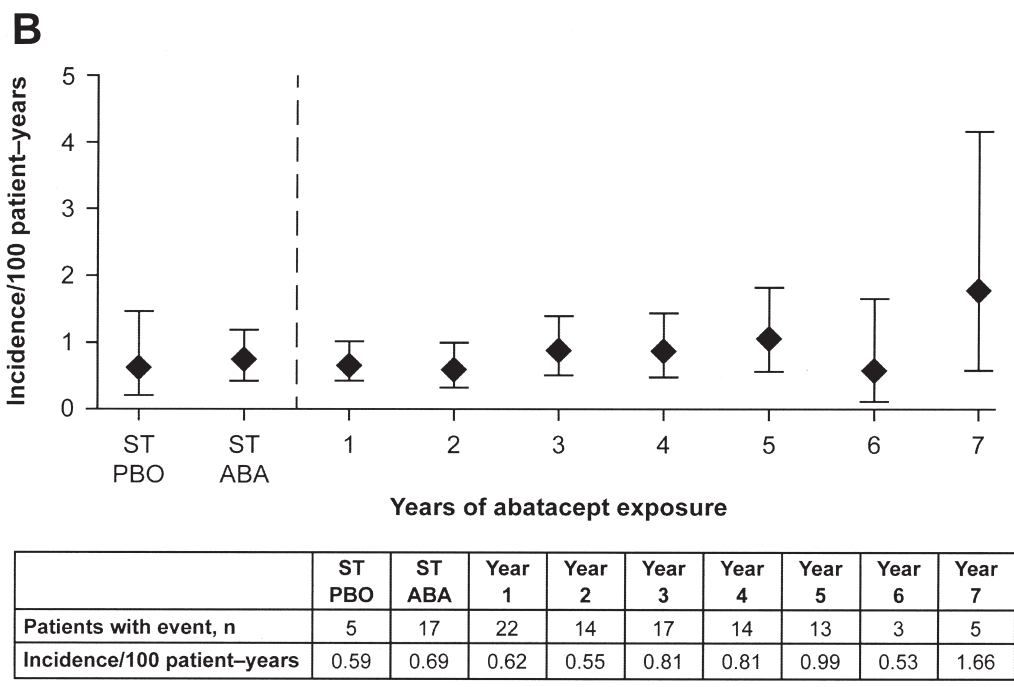

Figure 1. Incidence rates of hospitalized infections (A) and malignancies excluding nonmelanoma skin cancer (B) in the intravenous (IV) abatacept and placebo short-term period and the IV abatacept cumulative period by time interval. Years 1, 2, 3, 4, 5, 6, and 7 of exposure relate to Days 1-360, 361-720, 721-1080, 1081-1440, 1441-1800, 1801-2160, and 2161-last, respectively. ST: short-term; PBO: placebo; ABA: abatacept.

nonmelanoma skin cancer (NMSC)] were similar for IV abatacept- and placebo-treated patients during the short-term period (Table 6). During the cumulative period, the IR of malignancies (excluding NMSC) remained low and relatively consistent over time (Table 6, Figure 1B). Lymphomas were reported in 9 patients, including 3 classified as "lymphoma" (not otherwise specified), 2 each of diffuse large B cell lymphoma and extranodal marginal zone B cell lymphoma (MALT type), and single instances of non-Hodgkin's lymphoma and T cell lymphoma. The IR of NMSC was comparable for abatacept versus placebo in the short-term period, and was not increased for the cumulative relative to the short-term periods (Table 6).

The SIR for overall malignancies and tissue-specific malignancies indicated that the IR of these events were comparable between patients treated with abatacept during 
Table 6. Overview of malignancies in the short-term and cumulative analyses from the 8 integrated trials. Data show incidence rates (IR) per 100 patient-years (95\% Poisson CI).

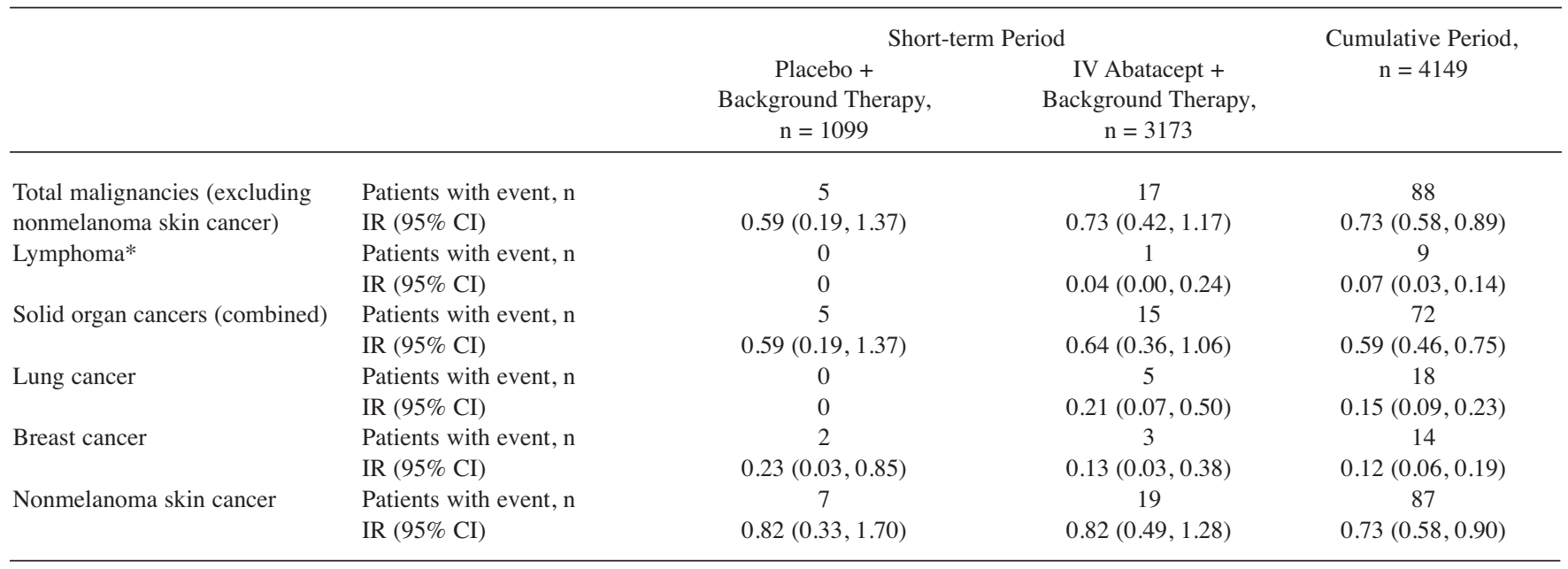

* Lymphoma refers to combined incidences of lymphoma, including extranodal marginal zone B cell lymphoma (MALT type), diffuse large B cell lymphoma, T cell lymphoma, and non-Hodgkin's lymphoma. IV: intravenous.

the cumulative period and the RA comparison cohorts (Table 7). The number of observed malignancies (excluding NMSC) was also similar to that expected based on the US general population (Table 7). As suggested by the SIR, breast cancer and colorectal cancer were observed less frequently, and lung cancer and lymphoma more frequently in IV abatacept-treated patients compared with the US general population, although the confidence interval for lung cancer included unity (Table 7).

Cardiac disorders. For cardiac disorders that were considered SAE, the IR was 1.42/100 patient-years (95\% CI $0.98,1.99 ; \mathrm{n}=33$ ) for IV abatacept and 2.24/100 patient-years $(95 \%$ CI $1.34,3.50 ; \mathrm{n}=19)$ for placebo during the short-term period. The most common events in the abatacept versus placebo groups were congestive cardiac failure (0.21 vs $0.59 / 100$ patient-years) and myocardial infarction (MI; 0.21 vs 0.23 patient-yrs). During the cumulative period, the IR for serious cardiac disorders was $1.22 / 100$ patient-yrs, with the most common event being MI
(0.27/100 patients-yrs). The annual IR for SAE cardiac disorders remained stable with increasing abatacept exposure (data not shown).

Autoimmune adverse events. The IR of autoimmune AE was $2.64 / 100$ patient-years $(95 \%$ CI 2.02, 3.39; $\mathrm{n}=61)$ in IV abatacept-treated and $1.55 / 100$ patient-years $(95 \%$ CI 0.83 , $2.65 ; \mathrm{n}=13$ ) in placebo-treated patients during the short-term period; the majority were mild or moderate. The most common events in the abatacept versus placebo groups were psoriasis ( 0.60 vs $0 / 100$ patient-yrs, respectively); vasculitis ( 0.34 vs $0.24 / 100$ patient-yrs); uveitis ( 0.26 vs 0/100 patient-yrs); Sjögren syndrome (SS; 0.26 vs $0.36 / 100$ patient-yrs); Raynaud phenomenon (0.21 vs $0.12 / 100$ patient-yrs); sicca syndrome (0.17 vs $0.12 / 100$ patient-yrs), and leukocytoclastic vasculitis (0.04 vs 0.24 patient-yrs). Five abatacept-treated patients and 1 placebo-treated patient reported autoimmune $\mathrm{AE}$ considered severe (abatacept: psoriasis, leukocytoclastic vasculitis, Raynaud phenomenon, uveitis, and scleritis; placebo: vasculitis).

Table 7. Standardized incidence ratios (SIR) for selected malignancies in the intravenous abatacept cumulative period compared with external rheumatoid arthritis (RA) cohorts and the US general population. Data are SIR (95\% CI). SIR are calculated by comparing the number of malignancies in the intravenous abatacept cumulative period with the expected values from the external cohorts, with SIR below 0 indicating reduced incidence with abatacept versus comparator.

\begin{tabular}{lcccc}
\hline & & RA Cohorts & & US General Population \\
& $\mathrm{BC}^{22} *$ & GPRD $^{21}$ & \\
\hline All malignancies excluding NMSC & $0.42(0.33,0.51)$ & - & $1.11(0.89,1.36)$ & $0.99(0.80,1.22)$ \\
$\quad$ Lung cancer & $0.59(0.35,0.94)$ & $1.26(0.75,1.99)$ & $1.08(0.64,1.71)$ & $1.59(0.94,2.52)$ \\
Lymphoma & $0.67(0.30,1.27)$ & $0.95(0.43,1.80)$ & $1.30(0.59,2.46)$ & $2.49(1.14,4.73)$ \\
Breast cancer & $0.34(0.18,0.56)$ & $0.42(0.23,0.70)$ & $0.71(0.39,1.20)$ & $0.62(0.34,1.03)$ \\
Colorectal cancer & $0.19(0.04,0.54)$ & $0.41(0.08,1.19)$ & $0.52(0.10,1.51)$ & $0.37(0.07,1.07)$ \\
\hline
\end{tabular}

* Data for US general population taken from the Surveillance Epidemiology and End Results database ${ }^{22}$. BC: British Columbia; NDB: National Data Bank for Rheumatic Diseases; GPRD: General Practice Research Database; NMSC: nonmelanoma skin cancer. 
Consistent with the short-term period, the IR of autoimmune $\mathrm{AE}$ in the cumulative period was $1.99 / 100$ patient-years $(95 \%$ CI 1.74, 2.26; $\mathrm{n}=232)$. The most common events included psoriasis ( $0.57 / 100$ patient-yrs), SS $(0.19 / 100$ patient-yrs), vasculitis $(0.18 / 100$ patient-yrs $)$, erythema nodosum $(0.13 / 100$ patient-yrs $)$, and episcleritis $(0.12 / 100$ patient-yrs). One case of multiple sclerosis (MS), 5 cases of systemic lupus erythematosus (SLE), and 1 case of lupus-like syndrome occurred. The patient with MS exhibited undiagnosed symptoms prior to enrollment. One patient with SLE and 1 with lupus-like syndrome were retrospectively found to have antinuclear or anti-double-stranded DNA antibodies prior to abatacept treatment.

Respiratory events. Given the inclusion of patients with respiratory comorbidities from the ASSURE trial into this pooled analysis, the occurrence of respiratory events is also of interest. Serious respiratory, thoracic, and mediastinal disorders occurred in 24 patients $(0.8 \%)$ in the pooled short-term periods at an IR of $1.03(95 \%$ CI $0.66,1.53)$. The most common serious events were chronic obstructive pulmonary disease (COPD) and pleural effusion, which were reported in 13 patients $(0.4 \%)$ each in the pooled short-term periods, at an IR of 0.56 (95\% CI 0.30, 0.96) each. During the cumulative short-term and LTE periods, serious respiratory, thoracic, and mediastinal disorders were reported in 97 patients (2.3\%) at an IR of 0.81 (95\% CI 0.65 , $0.98)$. The most common serious events were pulmonary embolism, which occurred in 11 patients $(0.3 \%$; IR 0.09 , $95 \%$ CI $0.05,0.16)$, COPD, pleural effusion, and respiratory failure, which all occurred in 10 patients each $(0.2 \%$; IR $0.08,95 \%$ CI $0.04,0.15$ each).

Of interest, interstitial lung disease (ILD) occurred in 2 abatacept-treated patients $(0.1 \%)$ in the pooled short-term period, an IR of 0.09 (95\% CI 0.01, 0.31), compared with no events in the control group. During the pooled LTE periods, ILD was reported in 11 patients $(0.3 \%)$, an IR of 0.11 (95\% CI 0.06, 0.20).

Acute infusional adverse events. Acute infusional AE were defined as events occurring $\leq 1 \mathrm{~h}$ after onset of infusion. The timing of infusional $\mathrm{AE}$ was recorded during the short-term portion of the phase III but not the phase II trials, yielding 3812 patients evaluable for acute infusional $\mathrm{AE}(\mathrm{n}=2868$ IV abatacept; $n=944$ placebo). The IR of acute infusional $\mathrm{AE}$ was $11.66 / 100$ patient-years in abatacept-treated patients and 9.97/100 patient-years in placebo-treated patients during the short-term period. The most common events reported for abatacept versus placebo were dizziness ( 2.35 vs $1.53 / 100$ patient-yrs), headache ( 2.10 vs $1.67 / 100$ patient-yrs), hypertension (1.31 vs $0.69 / 100$ patient-yrs), nausea (1.27 vs $1.25 / 100$ patient-yrs), increased blood pressure ( 0.97 vs $0.69 / 100$ patient-yrs), flushing (0.78 vs $0.28 / 100$ patient-yrs), infusion site pain (0.19 vs $0.97 / 100$ patient-yrs), and chills (0.05 vs $0.69 / 100$ patient-yrs). Most events were mild to moderate, none were considered serious, and few patients discontinued $(0.4 \%$ abatacept; $0.2 \%$ placebo).

The IR of acute infusional $\mathrm{AE}$ in the cumulative period (evaluated in 6 studies; $\mathrm{n}=3755,9662$ patient-yrs of exposure) was $3.90 / 100$ patient-years. The most common events included dizziness $(0.67 / 100$ patient-yrs $)$, headache $(0.66 / 100$ patient-yrs), hypertension $(0.61 / 100$ patient-yrs $)$, nausea (0.38/100 patient-yrs), and increased blood pressure $(0.34 / 100$ patient-yrs). Events became less common over time, typically occurring within the first few months of treatment.

\section{DISCUSSION}

This analysis of safety data from 8 clinical trials included 4149 patients treated with IV abatacept, with a cumulative exposure of 12,132 patient-years. This represents the largest and longest analysis of its kind with IV abatacept to date. Abatacept had low IR for SAE, including serious infections, malignancies, cardiac disorders, autoimmune events, and infusion reactions, relative to treatment with placebo in the cumulative short-term period. IR did not increase with increasing exposure, and abatacept was not associated with an increased risk of hospitalized infection or malignancy versus the DMARD-treated RA populations.

Previous studies $15,24,25,26,27$ have demonstrated an increase in serious infections, such as pneumonia and TB, in patients receiving some anti-TNF therapies compared with other biologic or nonbiologic DMARD. The IR of serious infection among patients treated with IV abatacept presented in our study was similar to, or less than, that previously reported in other integrated or pooled safety analyses of biologic agents in $\mathrm{RA}^{28,29}$. A recent metaanalysis reported that the OR for serious infection in abatacept-treated patients was not significantly increased versus placebo-treated patients (OR 1.35, 95\% CI 0.78, $2.32)^{30}$. It should be noted that published studies have shown that treating patients with combination biologic therapy, such as abatacept plus etanercept or anakinra plus etanercept, increases the frequency of serious infection ${ }^{14,31}$. Thus concomitant use of other biologics alongside abatacept is contraindicated.

The IR of TB and other opportunistic infections during abatacept treatment reported here was relatively low, with no increases over time, and was toward the lower end of the range reported for other biologic agents in patients with $\mathrm{RA}^{32,33,34}$. All TB events occurred in patients living in countries with high endemic rates (Mexico, Brazil, Portugal, Thailand, and South Africa). These data are supported by findings from the ATTEST study, which evaluated abatacept and infliximab in the same clinical trial setting, and reported fewer serious infections with abatacept versus infliximab, respectively, over 12 months (1.9\% vs $8.5 \%)$, including fewer serious opportunistic infections ( 0 vs 5 events) $)^{15}$.

Personal non-commercial use only. The Journal of Rheumatology Copyright (C) 2013. All rights reserved. 
In addition, patients with RA are also reported to have about a 2-fold greater rate of hospitalized infections than patients without $\mathrm{RA}^{35}$. These data suggest that the IR of hospitalized infections with abatacept is not increased over time, and is lower than published rates for patients treated with nonbiologic DMARD (9.57/100 patient-yrs $)^{35,36}$.

A metaanalysis of patients with RA suggested an increased risk for lymphoma and lung cancer, and a decreased risk for colorectal and breast cancer compared with the general population ${ }^{37}$. Data from our study of abatacept-treated patients are consistent with these findings. However, the combined SIR for all forms of lung cancer were not statistically different from unity versus the external RA cohorts and the US general population, suggesting that there was no overall increased risk for lung cancer with abatacept treatment.

The cumulative IR for lymphoma was increased compared with the US general population, but was not increased compared with the external RA cohorts. Several patients had diffuse B cell lymphoma, which is known to occur with increased frequency in patients with $\mathrm{RA}^{37}$. IR of lymphoma observed here were comparable with those observed with other biologic agents ${ }^{24,30}$, and registry data suggest that biologics are not associated with any further increase in the already elevated lymphoma occurrence in $\mathrm{RA}^{38}$.

Autoimmune AE associated with IV abatacept exposure were rare; the most common autoimmune $\mathrm{AE}$ reported was psoriasis. A small phase I study of patients with psoriasis vulgaris reported no evidence of worsening of psoriasis with abatacept treatment ${ }^{39}$. Thus, the relationship between psoriasis and abatacept treatment in patients with RA is unclear. The cases of SS observed here were likely to be secondary to RA, and there was no clear definition of primary or secondary SS used in the trials.

Of note, the ASSURE study was included in this pooled analysis, which included patients with comorbidities, who are more representative of patients typically encountered in clinical practice ${ }^{5}$. In ASSURE, relatively comparable frequencies of SAE and discontinuations due to $\mathrm{AE}$ were reported for abatacept- and placebo-treated patients presenting with congestive heart failure or asthma compared to patients without comorbidities ${ }^{5}$. They did find, however, that for patients with COPD or diabetes, SAE frequencies were higher in abatacept- versus placebo-treated patients, driven by increases in respiratory and infection-related events in patients with COPD, and by musculoskeletal disorders and injury in patients with diabetes ${ }^{5}$. The occurrence of certain respiratory events such as COPD is of interest in patients with RA. Only a small number of patients included in this analysis had underlying COPD - those included from ASSURE. Data presented here indicate that in this pooled analysis, the overall IR of COPD did not increase in the cumulative relative to the short-term treatment periods, suggesting no increased risk of COPD with continued exposure. There is also a reported increased risk of ILD for patients with RA relative to the general population, with 10-, 20-, and 30-year cumulative IR for probable and definite ILD of $3.5 \%, 6.3 \%$, and $7.7 \%$, respectively (adjusted for the competing risk of death), conveying a lifetime risk of $\sim 10 \%{ }^{40}$. In this pooled analysis, the IR of ILD was low during both the short-term and LTE periods, with no apparent increase in risk over time.

Findings from this pooled analysis confirm the observations made during the individual trials, but in a larger pooled patient population and over a longer timeframe than previously reported, confirming the well-tolerated safety profile of IV abatacept in patients with established moderate to severe RA. Observations made across clinical trials suggest that abatacept may have an improved safety profile when administered earlier in the disease progression ${ }^{2,4,7}$. The database for this longterm analysis was initiated prior to the phase III study of abatacept in patients with early RA, and thus those data are not included here; however, findings from that study ${ }^{7}$ suggest that abatacept plus MTX is well tolerated in MTX-naive patients with early RA, with no increase in the rates of SAE, serious infections, and autoimmune events from Years 1 to 2. Although treatment patterns are shifting toward earlier, more aggressive intervention, the majority of patients treated in the clinic will have failed MTX treatment prior to initiating treatment with a biologic DMARD such as abatacept, as per internationally accepted guidelines. Thus, patients included in this analysis are more representative of those seen in clinical practice, making these findings particularly clinically relevant.

The strengths of this integrated analysis include a database of sufficient size and duration of IV abatacept exposure to detect rare events. Nevertheless, the data should be interpreted within the context of the analyses' limitations. Clinical trial conditions do not always reflect real-world experience; some patient types are excluded because of preexisting illnesses or concomitant medications, and patients generally do not have as many underlying comorbidities. Such differences between a clinical trial patient population and the patient population enrolled in registries may limit the ability to compare IR between these 2 populations. However, this pooled analysis included data from both the ASSURE and ARRIVE studies, which were designed to include patients more representative of those seen in clinical practice, including patients with comorbidities, as discussed above for the ASSURE trial ${ }^{5}$, and those from the ARRIVE study without anti-TNF washout who may have had positive PPD testing at baseline ${ }^{17}$.

In this analysis, safety is described exactly as reported in the clinical trials included, with no statistical design correction or weighting applied, which may have been of benefit given the different patient populations included in each study. There are additional well-documented issues 
with reporting LTE clinical trial data, with a bias toward reporting outcomes only for those patients who remain in the trial and are, therefore, responding to and tolerating therapy. Patients who do not respond and discontinue treatment early are often those at higher risk of AE, and could account for the higher IR of safety events in the short-term versus LTE periods. However, events that occurred up to 56 days post-discontinuation were included in this analysis, and given that abatacept has a half-life of around 14 days in patients with RA, this should allow the recording of many events. Given that some patients discontinued abatacept therapy during the clinical trials pooled for this analysis, patients would have contributed different patient-years of exposure to the analysis. The median exposure time, however, was $\sim 2.5$ years, with $\sim 30 \%$ of the 4149 patients treated in the cumulative study period exposed for $\geq 5$ years. Further, there was a relatively low frequency of discontinuation due to $\mathrm{AE}$ in the pooled short-term periods discussed here, and although the IR for abatacept was numerically higher than that for placebo, $95 \%$ CI did overlap. Importantly, the objective of this analysis was to evaluate safety with prolonged abatacept treatment, given the chronic expression of the disease and in light of the shift toward earlier treatment, resulting in patients receiving treatment for more extended periods of time. The limits of this analysis provide such an assessment.

Finally, a further tolerability issue with biologic administration that has not been covered here is that of immunogenicity. Generally, abatacept has demonstrated low immunogenicity rates, with any occurrence being transient and with low titer ${ }^{41}$. A pooled longterm analysis of immunogenicity with abatacept is being performed, and will be given in a separate report.

The integrated analyses presented here, conducted in a large patient population, show that with increasing exposure, IV abatacept demonstrates a consistent safety profile with no unexpected or new safety signals occurring during longer-term followup. Given that many patients will continue biologic treatment for long periods of time, these data are of particular relevance to clinicians using abatacept in daily clinical practice.

\section{ACKNOWLEDGMENT}

The authors thank Keqin $\mathrm{Qi}, \mathrm{PhD}$, for his contribution to the study. Professional medical writing and editorial assistance for this report was provided by Caudex Medical.

\section{REFERENCES}

1. Kremer JM, Dougados M, Emery P, Durez P, Sibilia J, Shergy W, et al. Treatment of rheumatoid arthritis with the selective costimulation modulator abatacept: Twelve-month results of a phase IIb, double-blind, randomized, placebo-controlled trial. Arthritis Rheum 2005;52:2263-71.

2. Kremer JM, Genant HK, Moreland LW, Russell AS, Emery P, Abud-Mendoza C, et al. Effects of abatacept in patients with methotrexate-resistant active rheumatoid arthritis: A randomized trial. Ann Intern Med 2006;144:865-76.

3. Kremer JM, Westhovens R, Leon M, Di Giorgio E, Alten R, Steinfeld $\mathrm{S}$, et al. Treatment of rheumatoid arthritis by selective inhibition of T-cell activation with fusion protein CTLA4Ig. N Engl J Med 2003;349:1907-15.

4. Genovese MC, Becker JC, Schiff M, Luggen M, Sherrer Y, Kremer $\mathrm{J}$, et al. Abatacept for rheumatoid arthritis refractory to tumor necrosis factor alpha inhibition. N Engl J Med 2005;353:1114-23.

5. Weinblatt M, Combe B, Covucci A, Aranda R, Becker JC, Keystone E. Safety of the selective costimulation modulator abatacept in rheumatoid arthritis patients receiving background biologic and nonbiologic disease-modifying antirheumatic drugs: A one-year randomized, placebo-controlled study. Arthritis Rheum 2006;54:2807-16.

6. Ruperto N, Lovell DJ, Quartier P, Paz E, Rubio-Pérez N, Silva CA, et al. Abatacept in children with juvenile idiopathic arthritis: A randomised, double-blind, placebo-controlled withdrawal trial. Lancet 2008;372:383-91.

7. Westhovens R, Robles M, Ximenes AC, Nayiager S, Wollenhaupt J, Durez $\mathrm{P}$, et al. Clinical efficacy and safety of abatacept in methotrexate-naive patients with early rheumatoid arthritis and poor prognostic factors. Ann Rheum Dis 2009;68:1870-7.

8. Wallis RS, Broder MS, Wong JY, Hanson ME, Beenhouwer DO. Granulomatous infectious diseases associated with tumor necrosis factor antagonists. Clin Infect Dis 2004;38:1261-5.

9. De Bandt M, Sibilia J, Le Loet X, Prouzeau S, Fautrel B, Marcelli $\mathrm{C}$, et al. Systemic lupus erythematosus induced by anti-tumour necrosis factor alpha therapy: A French national survey. Arthritis Res Ther 2005;7:R545-51.

10. Ramos-Casals M, Brito-Zeron P, Munoz S, Soria N, Galiana D, Bertolaccini L, et al. Autoimmune diseases induced by TNF-targeted therapies: Analysis of 233 cases. Medicine 2007;86:242-51.

11. Bongartz T, Sutton AJ, Sweeting MJ, Buchan I, Matteson EL, Montori V. Anti-TNF antibody therapy in rheumatoid arthritis and the risk of serious infections and malignancies: Systematic review and meta-analysis of rare harmful effects in randomized controlled trials. JAMA 2006;295:2275-85.

12. Wolfe F, Michaud K. Biologic treatment of rheumatoid arthritis and the risk of malignancy: Analyses from a large US observational study. Arthritis Rheum 2007;56:2886-95.

13. Alonso-Ruiz A, Pijoan JI, Ansuategui E, Urkaregi A, Calabozo M, Quintana A. Tumor necrosis factor alpha drugs in rheumatoid arthritis: Systematic review and metaanalysis of efficacy and safety. BMC Musculoskelet Disord 2008;9:52.

14. Weinblatt M, Schiff M, Goldman A, Kremer J, Luggen M, Li T, et al. Selective costimulation modulation using abatacept in patients with active rheumatoid arthritis while receiving etanercept: A randomised clinical trial. Ann Rheum Dis 2007;66:228-34.

15. Schiff M, Keiserman M, Codding C, Songcharoen S, Berman A, Nayiager S, et al. Efficacy and safety of abatacept or infliximab vs placebo in ATTEST: A phase III, multi-centre, randomised, double-blind, placebo-controlled study in patients with rheumatoid arthritis and an inadequate response to methotrexate. Ann Rheum Dis 2008;67:1096-103.

16. Buch MH, Boyle DL, Rosengren S, Saleem B, Reece RJ, Rhodes LA, et al. Mode of action of abatacept in rheumatoid arthritis patients having failed tumour necrosis factor blockade: A histological, gene expression and dynamic magnetic resonance imaging pilot study. Ann Rheum Dis 2009;68:1220-7.

17. Schiff M, Pritchard C, Huffstutter JE, Rodriguez-Valverde V, Durez $\mathrm{P}$, Zhou X, et al. The 6-month safety and efficacy of abatacept in patients with rheumatoid arthritis who underwent a washout after 
anti-tumour necrosis factor therapy or were directly switched to abatacept: The ARRIVE trial. Ann Rheum Dis 2009;68:1708-14.

18. Lacaille D, Anis AH, Guh DP, Esdaile JM. Gaps in care for rheumatoid arthritis: A population study. Arthritis Rheum 2005;53:241-8.

19. PharMetrics Integrated Database. Danbury, CT: IMS. [Internet. Accessed February 27, 2013.] Available from:

http://www.imshealth.com/portal/site/ims/menuitem.d248e29c8658 9c9c30e81c033208c22a/?vgnextoid=d6952a2e23264310 VgnVCM 1 00000ed152ca2RCRD\&vgnextfmt=default

20. Wolfe F, Michaud K. The effect of methotrexate and anti-tumor necrosis factor therapy on the risk of lymphoma in rheumatoid arthritis in 19,562 patients during 89,710 person-years of observation. Arthritis Rheum 2007;56:1433-9.

21. Lawson DH, Sherman V, Hollowell J. The General Practice Research Database. Scientific and Ethical Advisory Group. QJM 1998;91:445-52

22. National Cancer Institute. Surveillance, Epidemiology and End Results Program. SEER*Stat Database: Incidence - SEER 17 2000-2007. Bethesda, MD: US Department of Health and Human Services. [Internet. Accessed February 27, 2013.] Available from: http://seer.cancer.gov/canques/incidence.html

23. Simon TA, Smitten AL, Franklin J, Askling J, Lacaille D, Wolfe F, et al. Malignancies in the rheumatoid arthritis abatacept clinical development programme: An epidemiological assessment. Ann Rheum Dis 2009;68:1819-26.

24. Koike T, Harigai M, Inokuma S, Ishiguro N, Ryu J, Takeuchi T, et al. Postmarketing surveillance of safety and effectiveness of etanercept in Japanese patients with rheumatoid arthritis. Mod Rheumatol 2011;21:343-51.

25. Komano Y, Tanaka M, Nanki T, Koike R, Sakai R, Kameda H, et al. Incidence and risk factors for serious infection in patients with rheumatoid arthritis treated with tumor necrosis factor inhibitors: A report from the Registry of Japanese Rheumatoid Arthritis Patients for Longterm Safety. J Rheumatol 2011;38:1258-64.

26. Singh JA, Wells GA, Christensen R, Tanjong Ghogomu E, Maxwell L, Macdonald JK, et al. Adverse effects of biologics: A network meta-analysis and Cochrane overview. Cochrane Database Syst Rev 2011;2:CD008794.

27. St. Clair EW, van der Heijde DM, Smolen JS, Maini RN, Bathon $\mathrm{JM}$, Emery P, et al. Combination of infliximab and methotrexate therapy for early rheumatoid arthritis: A randomized, controlled trial. Arthritis Rheum 2004;50:3432-43.

28. Burmester GR, Mease P, Dijkmans BA, Gordon K, Lovell D, Panaccione R, et al. Adalimumab safety and mortality rates from global clinical trials of six immune-mediated inflammatory diseases. Ann Rheum Dis 2009;68:1863-9.

29. Leombruno JP, Einarson TR, Keystone EC. The safety of anti-tumour necrosis factor treatments in rheumatoid arthritis: Meta and exposure-adjusted pooled analyses of serious adverse events. Ann Rheum Dis 2009;68:1136-45.

30. Salliot C, Dougados M, Gossec L. Risk of serious infections during rituximab, abatacept and anakinra treatments for rheumatoid arthritis: Meta-analyses of randomised placebo-controlled trials. Ann Rheum Dis 2009;68:25-32.
31. Genovese MC, Cohen S, Moreland L, Lium D, Robbins S, Newmark R, et al. Combination therapy with etanercept and anakinra in the treatment of patients with rheumatoid arthritis who have been treated unsuccessfully with methotrexate. Arthritis Rheum 2004;50:1412-9.

32. Dixon WG, Hyrich KL, Watson KD, Lunt M, Galloway J, Ustianowski A, et al. Drug-specific risk of tuberculosis in patients with rheumatoid arthritis treated with anti-TNF therapy: Results from the British Society for Rheumatology Biologics Register (BSRBR). Ann Rheum Dis 2010;69:522-8

33. Schiff MH, Burmester GR, Kent JD, Pangan AL, Kupper H, Fitzpatrick SB, et al. Safety analyses of adalimumab (HUMIRA) in global clinical trials and US postmarketing surveillance of patients with rheumatoid arthritis. Ann Rheum Dis 2006;65:889-94.

34. Tubach F, Salmon D, Ravaud P, Allanore Y, Goupille P, Bréban M, et al. Risk of tuberculosis is higher with anti-tumor necrosis factor monoclonal antibody therapy than with soluble tumor necrosis factor receptor therapy: The three-year prospective French Research Axed on Tolerance of Biotherapies registry. Arthritis Rheum 2009;60:1884-94.

35. Doran MF, Crowson CS, Pond GR, O'Fallon WM, Gabriel SE. Frequency of infection in patients with rheumatoid arthritis compared with controls: A population-based study. Arthritis Rheum 2002;46:2287-93.

36. Simon TA, Askling J, Lacaille D, Franklin J, Wolfe F, Covucci A, et al. Infections requiring hospitalization in the abatacept clinical development program: An epidemiological assessment. Arthritis Res Ther 2010;12:R67.

37. Smitten AL, Simon TA, Hochberg MC, Suissa S. A meta-analysis of the incidence of malignancy in adult patients with rheumatoid arthritis. Arthritis Res Ther 2008;10:R45.

38. Askling J, Baecklund E, Granath F, Geborek P, Fored M, Backlin $\mathrm{C}$, et al. Anti-tumour necrosis factor therapy in rheumatoid arthritis and risk of malignant lymphomas: Relative risks and time trends in the Swedish Biologics Register. Ann Rheum Dis 2009;68:648-53.

39. Abrams JR, Kelley SL, Hayes E, Kikuchi T, Brown MJ, Kang S, et al. Blockade of T lymphocyte costimulation with cytotoxic $\mathrm{T}$ lymphocyte-associated antigen 4-immunoglobulin (CTLA4Ig) reverses the cellular pathology of psoriatic plaques, including the activation of keratinocytes, dendritic cells, and endothelial cells. J Exp Med 2000;192:681-94.

40. Bongartz T, Nannini C, Medina-Velasquez YF, Achenbach SJ, Crowson CS, Ryu JH, et al. Incidence and mortality of interstitial lung disease in rheumatoid arthritis. A population-based study. Arthritis Rheum 2010;62:1583-91.

41. Weinblatt ME, Genovese MC, Schiff MH, Westhovens R, Alten R, Delaet I, et al. Immunogenicity is low and transient with intravenous abatacept therapy. Ann Rheum Dis 2012;71 Suppl $3: 377$. 